\title{
Valved jugular vein segments for right ventricular outflow tract reconstruction in young sheep
}

Paul Herijgers, $\mathrm{MD}^{\mathrm{a}}$

Shigeyuki Ozaki, MDa

Erik Verbeken, $M D^{\mathrm{b}}$

Alfons Van Lommel, $\mathrm{PhD}^{\mathrm{b}}$

Bart Meuris, MD

Emmanuel Lesaffre, $\mathrm{PhD}^{\mathrm{c}}$

Willem Daenen, MD ${ }^{\mathrm{a}}$

Willem Flameng, $\mathrm{MD}^{\mathrm{a}}$
From the Department of Cardiac Surgery and Center for Experimental Surgery and Anesthesiology, a the Department of Pathology, ${ }^{\mathrm{b}}$ and the Department of Biostatistics, ${ }^{\mathrm{c}}$ Katholieke Universiteit Leuven, Belgium.

Received for publication June 11, 2001; revisions requested Aug 14, 2001; revisions received Oct 2, 2001; accepted for publication Oct 8, 2001

Address for reprints: Willem Flameng, MD, CEHA, Provisorium I, Minderbroedersstraat 17, 3000 Leuven, Belgium (E-mail: willem.flameng@med.kuleuven.ac.be).

J Thorac Cardiovasc Surg 2002;124: 798-805

Copyright (C) 2002 by The American Association for Thoracic Surgery

0022-5223/2002 \$35.00+0 $\quad \mathbf{1 2 / 1 / 1 2 1 0 4 3}$

doi: $10.1067 / \mathrm{mtc} .2002 .121043$
Objective: This study was undertaken to investigate the degeneration and calcification of valved bovine jugular vein segments for right ventricular outflow tract reconstruction in juvenile sheep.

Methods: Seven valved bovine jugular vein conduits (Contegra model 220; VenPro Corporation, Irvine, Calif) and 3 control conduits (MH100; Medtronic, Inc, Minneapolis, Minn) were implanted in the pulmonary artery in young sheep. After 20 weeks the conduits were explanted and qualitatively analyzed by epicardial echocardiography, gross examination, $\mathrm{x}$-ray analysis, light microscopy, and transmission electron microscopy. Calcification was determined quantitatively by flame atomic absorption spectrometry.

Results: Two Contegra conduits could not be analyzed because of endocarditis. All other Contegra conduits functioned well, with preserved structure and minimal calcification. The control MH100 conduits exhibited extensive fibrous sheathing, with calcification of the aortic wall portion and the commissural part of the Hancock valve.

Conclusions: The Contegra conduit's performance was clearly superior to that of the control MH100 conduit when implanted in the pulmonary artery position in juvenile sheep for 5 months.

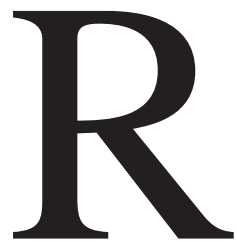

ight ventricular outflow tract reconstruction for congenital heart disease or restoration of continuity after pulmonary autograft transfer in the Ross procedure is generally performed with pulmonary homografts, the current gold standard. ${ }^{1-3}$ Unfortunately, suitable pulmonary homografts are often unavailable, especially for urgent operations and in small sizes. A durable valved conduit available off the shelf in a wide range of sizes could clearly fill a clinical need.

Xenograft valves have been used when no homografts were available in a number of instances. Typically, a Dacron polyester fabric graft with a stented porcine bioprosthesis has been chosen, ${ }^{1}$ but stentless aortic or pulmonary xenografts $^{4-7}$ have also been used, with mixed results.

Experimentally, we used a young sheep model with valve implantation in the pulmonary position to test several potentially suitable xenografts in right ventricular outflow tract reconstruction. ${ }^{8-10}$ An attractive conduit for its off-the-shelf availability and sizing is a valved segment of fixed bovine jugular vein. Few studies have analyzed the performance of this valved conduit. Ichikawa and coworkers ${ }^{11}$ described excellent results in adult dogs after 1 year of implantation with bovine 
jugular vein graft segments with trileaflet valves fixed with a hydrophilic polyepoxy compound. Bonhoeffer and associates $^{12}$ used specially made glutaraldehyde-fixed bovine jugular vein segments sutured in a stent for percutaneous implantation of a valve in pulmonary position in lambs. One of 7 successfully implanted valves showed calcification after 2 months, and 1 valve showed limited degeneration. No reports are available concerning the fate of this type of valved conduit in a standard juvenile sheep experimental model used for durability testing.

In this study we examined the degeneration characteristics of bovine valved jugular vein conduits conventionally fixed with glutaraldehyde (Contegra model 220; VenPro Corporation, Irvine, Calif) after 20 weeks of implantation in growing sheep younger than 6 months and compared them with those of a commercially available Dacron polyester fabric conduit with a bioprosthetic Hancock valve included (MH100, Medtronic, Inc, Minneapolis, Minn). This type of valved bovine jugular vein conduit has recently been introduced in Europe for clinical trials. ${ }^{13}$

\section{Materials and Methods}

All animals were cared for by a veterinarian in accordance with the Guide for the Care and Use of Laboratory Animals prepared by the Institute of Laboratory Animal Resources, National Research Council, published by the National Academy Press, revised 1996, and with Belgian legal requirements. The ethics committee of the Katholieke Universiteit Leuven approved the study. Young Lovenaar sheep, bred for this purpose and younger than 6 months, were selected.

\section{Valves Studied}

Seven bovine valved jugular vein conduits (Contegra model 220) were obtained from the manufacturer, and three Medtronic Hancock Model 100 Valved Conduits (MH100) were obtained from the manufacturer. The conduits were stored and handled as prescribed by the manufacturer.

\section{Implantation}

Valves were implanted by previously described methods. ${ }^{8}$ After premedication with ketamine, anesthesia was induced and maintained with halothane and nitrous oxide. Fentanyl was administered in bolus doses as necessary. Mechanical ventilation was instituted, and a left thoracotomy was performed in the second intercostal space. After intravenous administration of $3 \mathrm{mg} / \mathrm{kg}$ heparin, a pneumatic right ventricular assist system (Medos-HIA VAD; Medos-Helmholtz Institute, Aachen, Germany) was installed with the inflow cannula in the right atrium and the outflow cannula $1 \mathrm{~cm}$ before the pulmonary bifurcation. After transection of the pulmonary artery, the conduits were interposed with continuous 4-0 Prolene sutures (Ethicon, Inc, Somerville, NJ) for both proximal and distal anastomoses. Afterward the native pulmonary valve was destroyed by tearing two cusps with a clamp introduced through a purse-string suture placed at the sinuses. The chest was closed with a drain in the left pleural space. The animal was extubated immediately and brought to the recovery room.
Feeding was allowed immediately. Intravenous fluid administration was stopped after 2 hours. The chest drain was removed after 6 hours.

The animals received analgesia (piritramide) for the first 2 days according to regular schemes and received diuretics as necessary. A long-acting penicillin preparation and enoxaparine, $20 \mathrm{mg}$ twice daily, were administered for 6 days. Afterward the sheep were returned to the controlled animal facility, where their general health was checked daily.

\section{Explantation and Analysis}

Explantation was performed 20 weeks after implantation. After anesthesia, the thoracotomy was reopened and epicardial echocardiography was performed. Afterward $3 \mathrm{mg} / \mathrm{kg}$ heparin was administered, and the valve was excised together with proximal and distal parts of the sheep pulmonary artery.

Gross examination. Valves were grossly inspected from the inflow and outflow sides. Afterward the valve was longitudinally transected through the commissures. Each of the three specimens thus included prevalvular and postvalvular parts of the sheep pulmonary artery, together with a part of the bovine jugular vein wall (or Dacron polyester fabric with stent and porcine aortic wall, in the case of the MH100) and a cusp.

$X$-ray assessment. X-ray examination in two directions was performed under mammographic conditions to demonstrate and localize macroscopic calcifications.

Histologic examination. For histologic examination, a longitudinal transection of the specimen through the middle of a cusp was embedded in paraffin. Sections $4 \mu \mathrm{m}$ thick were routinely stained with hematoxylin and eosin, Masson trichrome stain for collagen, an elastic Von Giesson stain, a phosphotungstic acidhematoxylin stain for fibrin, and Von Kossa calcium staining.

Electron microscopy. For transmission electron microscopy, a cusp was divided into three parts, and the wall was divided in its inflow and outflow parts. From each of the five parts 3 to 10 samples ( $<1 \mathrm{~mm}$ in diameter) were embedded in Epon (Resolution Performance Products, Houston, Tex). Samples were taken serially, covering the entire thickness of the part. Sections $1 \mu \mathrm{m}$ thick were stained with toluidine blue and examined by light microscopy. Ultrathin sections were cut and stained with uranyl acetate and lead citrate. Sections were treated with $2 \%$ potassium pyroantimonate to demonstrate calcium. Grids were examined in a Philips CM10 transmission electron microscope (FEI Company Electron Optics, Eindhoven, The Netherlands). Random photographs were taken.

Quantitative calcium determination. Half of each segment was used for quantitative calcium determination. The cusps were divided into three parts: commissural area, basal part, and free edge. The wall was divided into two parts: inflow side and outflow part. Inflow and outflow parts of the wall were defined as the parts of the wall below and above the cusp. After lyophilization, the tissue was pulverized and desiccated to constant weight in an oven. Pulverized tissue was diluted in $20 \%$ hydrochloric acid at a ratio of $10 \mathrm{mg}$ dried tissue per $1 \mathrm{~mL}$ hydrochloric acid. Calcium content was measured by flame atomic absorption spectrometry and expressed in micrograms per milligram of dry weight. All three cusps of every valve were analyzed, and the mean calcium content was 

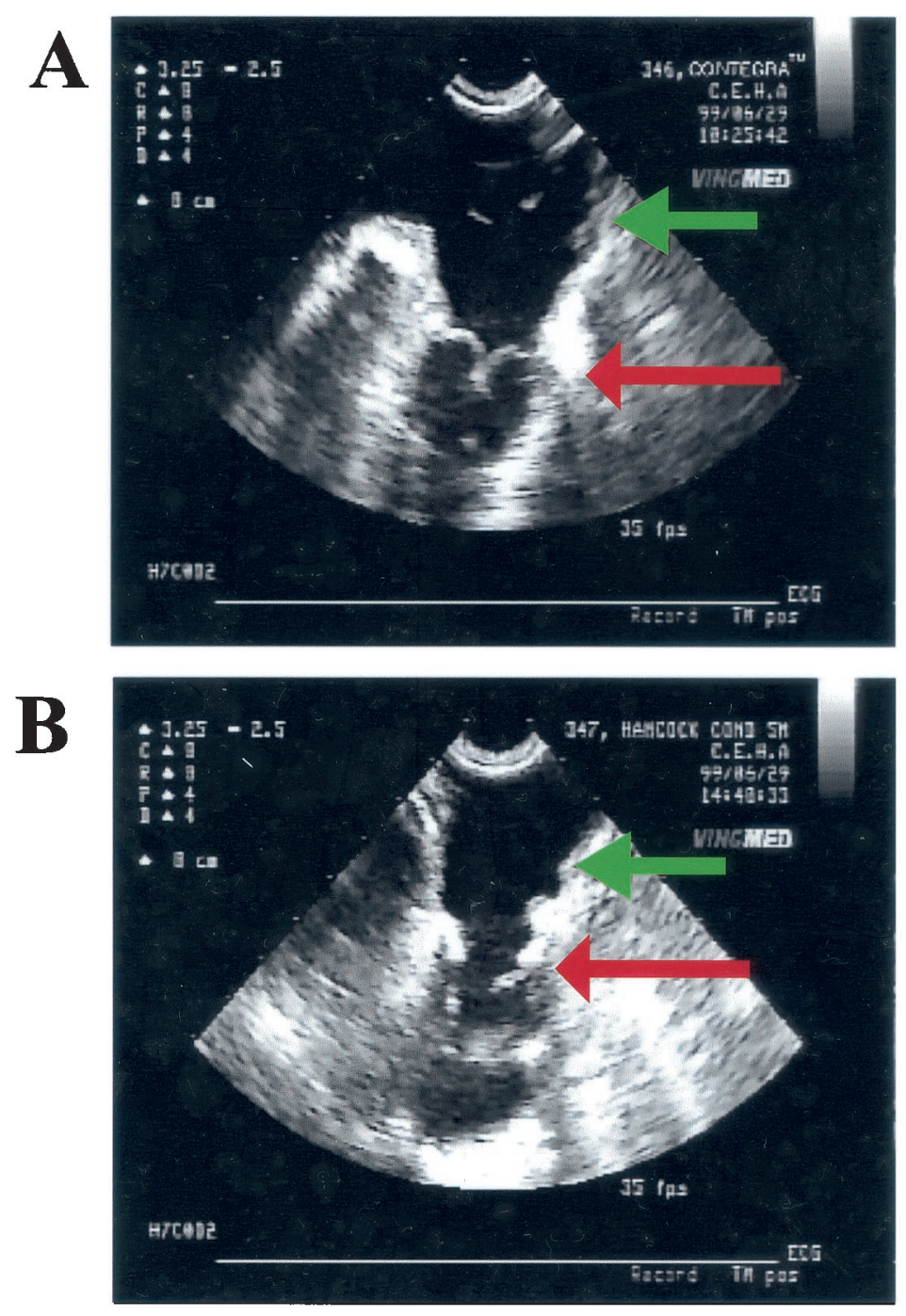

Figure 1. Representative epicardial echocardiographic diastolic images of Contegra conduit (A) and MH100 conduit (B) after 5 months of implantation. Cusps of conduits are located at level of red arrows; remnants of destroyed native pulmonary valve are located at level of green arrows. Note very large coaptation of cusps in Contegra conduit; one leaflet in MH100 conduit is immobile; other is thickened and relatively short.

calculated for each of the five parts with the three segments of a single valve. This mean was used for statistical analysis.

Data Management and Statistical Analysis

Data are expressed as medians with ranges. A Mann-Whitney $U$ test was performed on calcium content data for each of the five described parts of the conduits, with valve type as independent factor and calcium content as dependent factor. Statistical analysis was performed with STATISTICA 4.5 (StatSoft Inc, Tulsa, Okla).

\section{Results}

\section{Survival}

One sheep from the Contegra group died 103 days after implantation. Autopsy showed massive endocarditis (vegetations and destruction of the leaflets, confirmed histologi- cally) of the implanted conduit. The other valves were normal. All other sheep survived the prescribed period. At planned explantation, 1 Contegra valved conduit showed endocarditis and was excluded from the analysis.

\section{Preexplantation Epicardial Echocardiography (Figure 1)}

All 5 Contegra conduits without endocarditis showed laminar flow over the valve, without any sign of obstruction. All cusps were moving nicely. No regurgitation was present in 3 Contegra conduits, and slight regurgitation $(1+)$ was present in 2. A remarkable finding was the large height of coaptation of the leaflets ( $>8 \mathrm{~mm}$ in every valve).

Severe turbulence over the valve was present in 2 

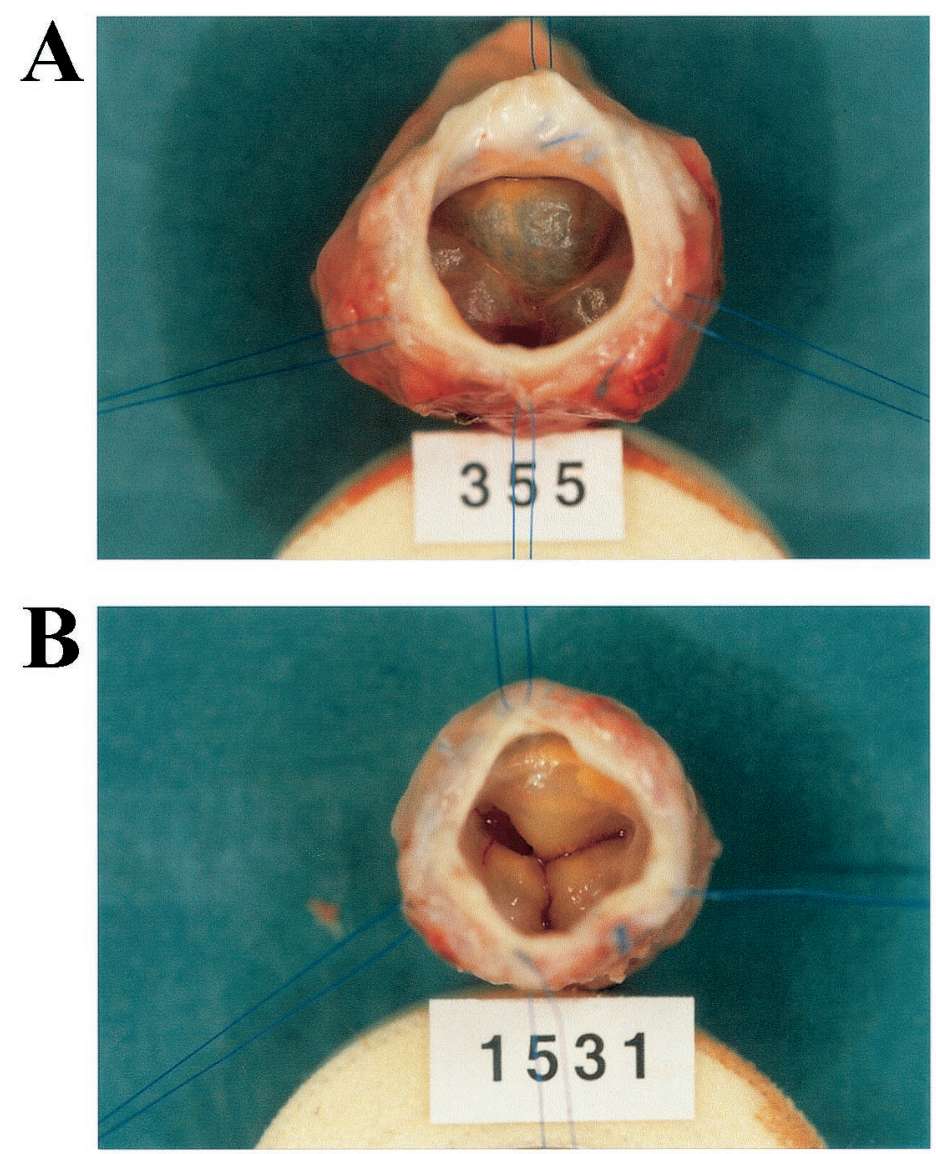

Figure 2. Representative macroscopic images of Contegra conduit (A) and MH100 conduit (B) seen from inflow (ventricular) side. Note difference between cusps, with perfect coaptation of thin cusps in Contegra conduit and lack of coaptation in thicker and stiffer cusps in MH100 conduit.

MH100 conduits, and laminar flow was present in only 1. Only 6 of 9 cusps were moving. Regurgitation was present in all valves $(1+, 2+$, and $4+)$. Coaptation height was always less than $2 \mathrm{~mm}$.

\section{Macroscopic Findings (Figure 2)}

All Contegra conduits showed nicely pliable, very thin leaflets that were without indurations, without fibrous overgrowth, and without deformation. Slight fibrous sheathing was present at the inside of the jugular vein wall but never extended onto the leaflets. In 1 conduit spots of calcification were visible in the bovine jugular vein wall, with calcium slightly protruding in the lumen, located approximately 2 $\mathrm{mm}$ above the hinge. In another conduit, discrete macroscopic spots of calcification were present in the jugular vein wall. Calcification was never seen in the leaflets.

In all three MH100 valves fibrous sheathing was extensive, completely encapsulating two of nine cusps and partially retracting two other cusps, with slight fibrous overgrowth of the remaining five cusps. In 2 valves there was evident lack of coaptation. The leaflets were deformed and retracted. The base of five cusps was clearly hardened, showing signs of calcification. One commissure between two cusps was fused, with a calcific nodule present. The aortic wall parts of the Hancock valves were severely calcified.

\section{X-ray Examination (Figure 3)}

Calcification was visible at the inflow and outflow suture lines of the Contegra conduits. No further calcification was visible in 3 Contegra conduits, whereas calcification was visible in scattered foci in the wall just above the cusps in the remaining 2 , in correspondence with the macroscopically suspected zones.

Severe calcification of the aortic wall portion of the MH100 conduits was always present. Calcification of the commissures was omnipresent, and slight calcification of the basal portions was seen in 6 of 9 leaflets.

\section{Histologic Examination (Figure 4)}

Bovine jugular vein valved conduits. The general morphology of the Contegra conduit was well preserved, with a 

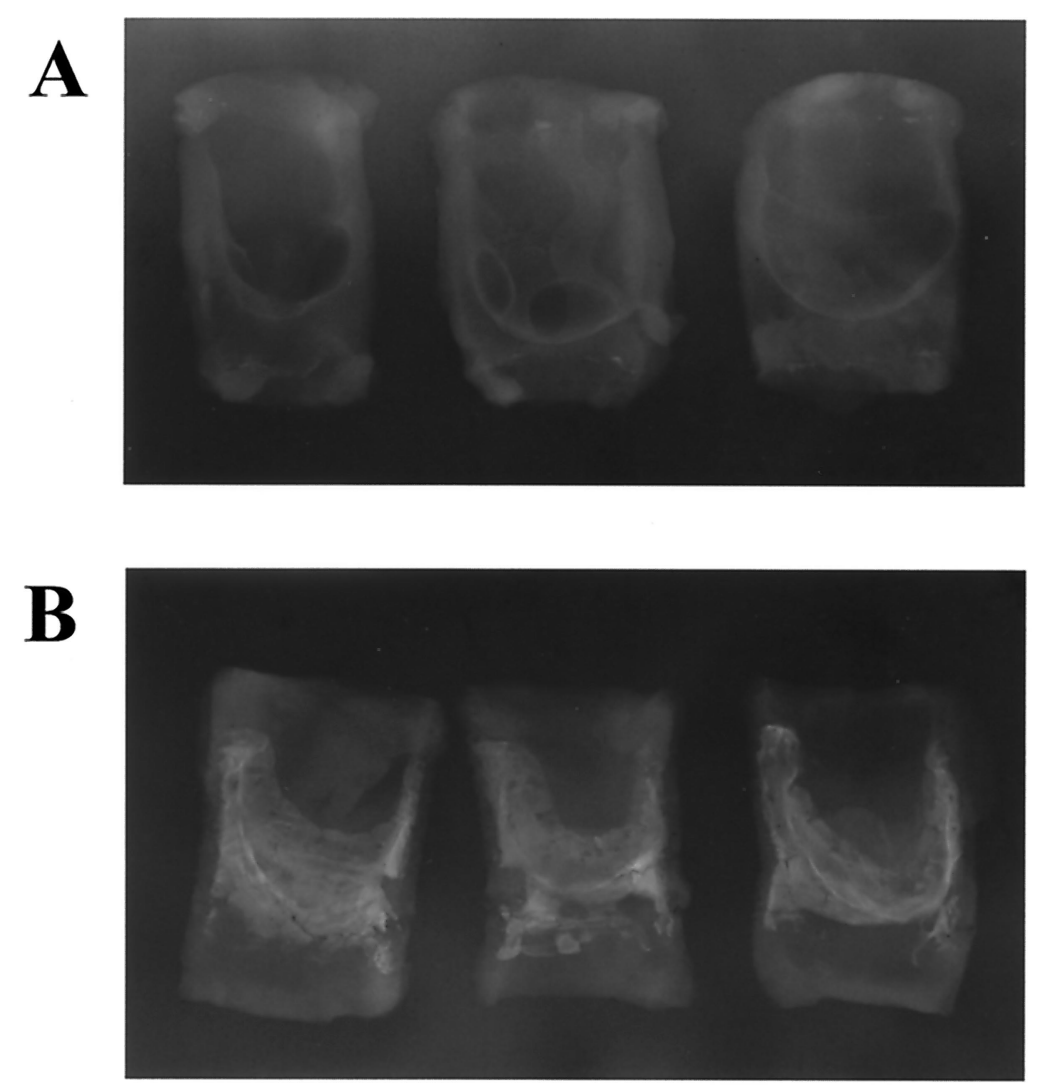

Figure 3. Representative x-ray images of Contegra conduit (A) and MH100 conduit (B) after longitudinal division of conduits into three segments. Note only minimal calcification near suture lines in Contegra conduits; calcification on wall portion of Hancock valves as well as at base of cusps is clearly visible in MH100 conduit.

remarkably thin and long leaflet only consisting of collagen bundles. A thin layer of fibrous tissue covered the inside of the wall at both its inflow and its outflow portions. In 1 valve slight fibrous overgrowth was seen on the base of the leaflets without attracting the leaflets to the wall. The macroscopic calcified protrusion in 1 Contegra conduit was a localized thickening of fibrous tissue covering the wall, with discrete calcification within this fibrous tissue. Calcification was never seen in the leaflets. Spots of calcification were visible in the conduit wall in 2 cases; in the other 3 cases calcification was present only near the sutures.

MH100. A fibrous sheath covered the inside of the inflow and outflow portions of the MH100, first covering the Dacron polyester fabric tube and closer to the valve the aortic wall portion of the Hancock valve. This sheath was thicker on the outflow portion than on the inflow portion. This thick, fibrous sheath covered considerable parts of the leaflets, causing attraction of the leaflets to the wall. The global architecture of the valve cusps was distorted in 2 valves, with thickening of the fibrosa and distortion of the three layers. Calcification was severe in the aortic wall portion of the Hancock valve, mainly in the elastin-rich area of the outflow part but also in the inflow part. Calcification was present at the base of the leaflet in 2 valves.

\section{Transmission Electron Microscopy}

The leaflets of the Contegra conduits consisted of a wellpreserved, wavy collagen pattern without signs of calcium deposition. The ultrastructure of the Hancock valves within the MH100 conduits was similar to the findings that we published previously elsewhere. ${ }^{14}$

\section{Quantitative Calcium Determination}

The calcium content was less in the walls of the Contegra conduits than in the walls of the MH100 conduits. Furthermore, the base and commissure of the cusps were also less calcified in the Contegra conduits than in the MH100 conduits (Table 1).

\section{Discussion}

The gold standard for reconstruction of the right ventricular outflow tract is a pulmonary homograft. ${ }^{2}$ These are scarce, however, especially in small sizes. When implanted in neonates or small infants, $75 \%$ have to be replaced within 5 

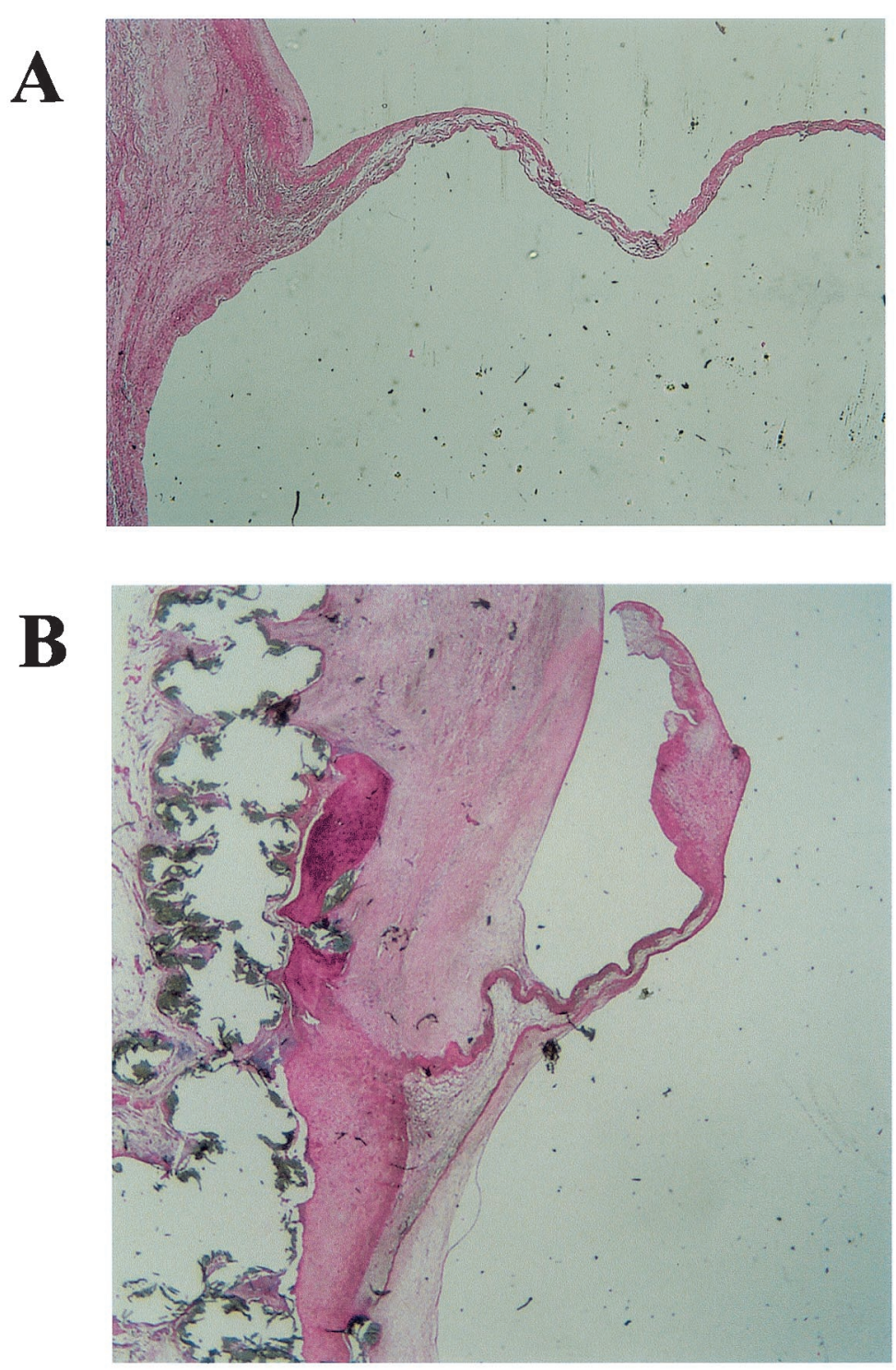

Figure 4. Representative histologic sections (hematoxylin and eosin stain) of Contegra conduit (A) and MH100 conduit (B). Note thin, fibrous sheathing in Contegra conduit, with thin cusp made almost entirely of collagen bundles. Outflow part and base of cusp of MH100 conduit are covered by thick, fibrous sheath. Architecture of Hancock cusp is distorted in its distal third. (Magnifications: $A, \times 11.3 ; \mathrm{B}, \times 10.6$.)

years, ${ }^{15}$ most often because the patient outgrows the size of the implanted homograft. ${ }^{1,15}$ Implanting xenografts in neonates and infants might increase the pool of homografts for use at a later age. Typically, a Dacron polyester fabric graft with a stented porcine bioprosthesis has been chosen for this, with acceptable results for neonates and infants because they outgrow the conduit before it has degenerated. ${ }^{1}$ Long-term clinical results of using stentless aortic or pulmonary xenografts as right ventricular outflow tract reconstruction are not available yet, and even after short-term follow-up a considerable number of heterografts exhibited obstruction of the conduit, often at the subvalvular level, supravalvular level, or both. ${ }^{4,7}$

Previously we were able to demonstrate slight to moderate calcification of the cusps together with more extensive calcification of the aortic wall of the Toronto SPV (St Jude Medical Inc, Minneapolis, Minn) and Biocor No-React II stentless aortic xenografts (BioCor, LLC, Belohorizonte, Brazil) implanted in the pulmonary position in young sheep. ${ }^{10}$ Although the cusps of Freestyle (Medtronic) valves remained pliable, the aortic wall portion had already calcified extensively after 3 months of implantation in this ju- 
TABLE 1. Calcium contents in different parts of the cusps and walls of the conduits, as measured by flame atomic absorption spectrophotometry

\begin{tabular}{lccc}
\hline & Contegra & MH100 & $P$ value \\
\hline Commissural part & $1.2(0.5-3.1)$ & $14.4(12.3-77.6)$ & .025 \\
Free edge & $1.0(0.6-3.0)$ & $1.9(1.6-3.6)$ & .101 \\
Basal part & $1.2(0.6-4.4)$ & $13.7(12.9-51.7)$ & .025 \\
Wall inflow part & $44.2(1.4-82.0)$ & $136.9(99.6-149.6)$ & .025 \\
Wall outflow part & $6.8(1.4-71.4)$ & $152.4(71.0-195.4)$ & .052 \\
\hline
\end{tabular}

Data are expressed as median and range.

venile sheep model. ${ }^{8}$ In a growing pig model, Schoof and colleagues ${ }^{16}$ showed even worse results with the Freestyle valve, with massive thickening of the cusps and valve dysfunction. In our sheep model, commercially available pericardial stentless conduits (Pericarbon; Sorin BioMedica, Saluggia, Italy) exhibited severe calcification and fibrous overgrowth of the cusps and conduit wall. ${ }^{8}$ The results of the Contegra conduit presented here are clearly superior to our earlier experimental observations of aortic or pericardial stentless xenografts.

As with every xenograft and allograft available, calcification occurred in the Contegra conduits. The amount of calcium deposition, however, was lower than that in the control valves. Anticalcification treatment might further decrease the calcification in these valves. It is remarkable that the conduit wall calcified more extensively than the cusps, a fact also seen in porcine aortic xenografts. Anticalcification treatment with amino-oleic acid does not seem to reduce calcification in aortic wall portions. ${ }^{8}$ So far, no reports have been published about the effects of anticalcification treatments on the jugular vein walls.

Comparison of these results of the Contegra conduit with those of other valve types in our model should be performed with caution, because the other valve types (except for the MH100 control group) were explanted after 3 or 6 months of implantation. The very large coaptation area between the cusps of the Contegra relative to all other implanted valve types is nonetheless a striking finding. This is caused by the difference in anatomy of the valve cusps, with the jugular vein valve cusps having on transection a horizontal part closing the orifice of the jugular vein and this horizontal part continuing with a relatively sharp angle in a vertical part responsible almost completely for the large coaptation. A second contributing factor is the lack of fibrous overgrowth on the leaflets, which caused retraction and leakage in all other valve types, including the Hancock valve in the MH100.

We chose the MH100 conduit as a control preparation because it is a commercially available conduit with right ventricular outflow tract reconstruction as its primary indication. As stated previously, allografts are still the gold standard for this indication, and in clinical practice the
Contegra conduit should be used in the absence of suitable allografts as an alternative to currently available bioprosthetic conduits, including the MH100. Only when mediumterm and long-term durability in clinical practice has been demonstrated might the Contegra conduit be indicated as an alternative to allografts in routine practice.

A word of caution should also be expressed about generalization of our results to reconstructions in patients with pulmonary hypertension or abnormalities in pulmonary artery anatomy that would cause distortion of the conduit. The conduit was implanted in our model as a straight tube in the pulmonary artery in sheep without pulmonary hypertension, so the hemodynamic and anatomic conditions were optimal for avoidance of pulmonary regurgitation. It is unlikely that optimal conditions can be reached in all clinical cases.

The incidence of endocarditis in our series was not surprising, because it has to be kept in mind that the valves were implanted in the pulmonary position with multiple perioperative and postoperative injections given and with surgical wounds that were difficult to cover adequately in a sterile way in awake sheep that rubbed the cage often. Endocarditis is encountered in most series of experiments in which valves are implanted in the right-sided position in sheep. ${ }^{8,16,17}$ Valves affected by endocarditis were not included in the analysis concerning degeneration and calcification because they showed completely different characteristics of destruction and calcification of the leaflets, as has also been stated by other authors. ${ }^{16}$

We conclude that the VenPro Contegra conduit had performance clearly superior to that of the control MH100 when implanted in pulmonary artery position in juvenile sheep for 5 months.

\section{References}

1. Homann M, Haehnel JC, Mendler N, Paek SU, Holper K, Meisner H, et al. Reconstruction of the RVOT with valved biological conduits: 25 years experience with allografts and xenografts. Eur J Cardiothorac Surg. 2000;17:624-30.

2. Daenen W, Gewillig M. Factors influencing medium-term results of right-sided cryopreserved homografts. J Heart Valve Dis. 1997;6:34754 .

3. Reddy VM, Rajasinghe HA, McElhinney DB, Hanley FL. Performance of right ventricle to pulmonary artery conduits after repair of 
truncus arteriosus: a comparison of Dacron-housed porcine valves and cryopreserved allografts. Semin Thorac Cardiovasc Surg. 1995;7: 133-8.

4. Brawn WJ. The use of a glutaraldehyde-preserved ovine pulmonary valve as a pulmonary valve substitute in infants. Semin Thorac Cardiovasc Surg. 1995;7:555-9.

5. Dittrich S, Alexi-Meskishvili VV, Yankah AC, Dähnert I, Meyer R, Hetzer R, et al. Comparison of porcine xenografts and homografts for pulmonary valve replacement in children. Ann Thorac Surg. 2000;70: 717-22.

6. Chard RB, Kang N, Andrews DR, Nunn GR. Use of the Medtronic Freestyle valve as a right ventricular to pulmonary artery conduit. Ann Thorac Surg. 2001;71:S361-4.

7. Levine AJ, Miller PA, Stumper OS, Wright JG, Silove ED, De Giovanni JV, et al. Early results of right-ventricular-pulmonary artery conduits in patients under 1 year of age. Eur J Cardiothorac Surg. 2001;19:122-6.

8. Herijgers P, Ozaki S, Verbeken E, Van Lommel A, Ràcz R, Zietkiewicz M, et al. Calcification characteristics of porcine stentless valves in juvenile sheep. Eur J Cardiothorac Surg. 1999;15:134-42.

9. Ozaki S, Herijgers P, Verbeken E, Van Lommel A, Perek B, Zietkiewicz M, et al. Are stentless aortic heterografts suitable for right ventricular outflow tract reconstruction? An experimental study in juvenile sheep. Semin Thorac Cardiovasc Surg. 1999;11 Suppl 1:17682.

10. Herijgers P, Ozaki S, Verbeken E, Van Lommel A, Jashari R, Nishida $\mathrm{T}$, et al. The No-React anticalcification treatment: a comparison of Biocor No-React II and Toronto SPV stentless bioprostheses im- planted in sheep. Semin Thorac Cardiovasc Surg. 1999;11 Suppl 1:171-5.

11. Ichikawa Y, Noishiki Y, Kosuge T, Yamamoto K, Kondo J, Matsumoto A. Use of a bovine jugular vein graft with natural valve for right ventricular outflow tract reconstruction: a one-year animal study. J Thorac Cardiovasc Surg. 1997;114:224-33.

12. Bonhoeffer P, Boudjemline Y, Saliba Z, Hausse AO, Aggoun Y, Bonnet $\mathrm{D}$, et al. Transcatheter implantation of a bovine valve in pulmonary position. Circulation. 2000;102:813-6.

13. Breymann T, Blanz U, Boethig D, Thies WR, Goerg R, Koertke H, et al. Bovine valved venous xenografts for RVOT-reconstruction: Results after 23 implantations. Presented at the VIII International Symposium on Cardiac Bioprostheses. Abstract 7166, Nov 3-5, 2000, Cancun, Mexico. Program and abstract book, ed. The Scientific Committee for the Advancement of Cardiac Bioprostheses. Paris; 2000.

14. Flameng W, Ozaki S, Yperman J, Herijgers P, Meuris B, Van Lommel $\mathrm{A}$, et al. Calcification characteristics of porcine stented valves in a juvenile sheep model. Ann Thorac Surg. 2001;71(5 Suppl):S401-5.

15. Forbess JM, Shah AS, St Louis JD, Jaggers JJ, Ungerleider RM. Cryopreserved homografts in the pulmonary position: determinants of durability. Ann Thorac Surg. 2001;71:54-60.

16. Schoof PH, Hazekamp MG, van Krieken HH, Huysmans HA. Pulmonary root replacement with the Freestyle stentless aortic xenograft in growing pigs. Ann Thorac Surg. 1998;65:1726-9.

17. Bernal JM, Rabasa JM, Cagigas JC, Val F, Revuelta JM. Behavior of mitral allografts in the tricuspid position in the growing sheep model. Ann Thorac Surg. 1998;65:1326-30. 